\title{
An Application of an Iterative Approach to DoD Software Migration Planning
}

John Bergey

Liam O'Brien

Dennis Smith

September 2002

Product Line Practice Initiative

Unlimited distribution subject to the copyright.

Technical Note

CMU/SEI-2002-TN-027 
The Software Engineering Institute is a federally funded research and development center sponsored by the U.S. Department of Defense.

Copyright 2002 by Carnegie Mellon University.

NO WARRANTY

THIS CARNEGIE MELLON UNIVERSITY AND SOFTWARE ENGINEERING INSTITUTE MATERIAL IS FURNISHED ON AN "AS-IS" BASIS. CARNEGIE MELLON UNIVERSITY MAKES NO WARRANTIES OF ANY KIND, EITHER EXPRESSED OR IMPLIED, AS TO ANY MATTER INCLUDING, BUT NOT LIMITED TO, WARRANTY OF FITNESS FOR PURPOSE OR MERCHANTABILITY, EXCLUSIVITY, OR RESULTS OBTAINED FROM USE OF THE MATERIAL. CARNEGIE MELLON UNIVERSITY DOES NOT MAKE ANY WARRANTY OF ANY KIND WITH RESPECT TO FREEDOM FROM PATENT, TRADEMARK, OR COPYRIGHT INFRINGEMENT.

Use of any trademarks in this report is not intended in any way to infringe on the rights of the trademark holder.

Internal use. Permission to reproduce this document and to prepare derivative works from this document for internal use is granted, provided the copyright and "No Warranty" statements are included with all reproductions and derivative works.

External use. Requests for permission to reproduce this document or prepare derivative works of this document for external and commercial use should be addressed to the SEI Licensing Agent.

This work was created in the performance of Federal Government Contract Number F19628-00-C-0003 with Carnegie Mellon University for the operation of the Software Engineering Institute, a federally funded research and development center. The Government of the United States has a royalty-free government-purpose license to use, duplicate, or disclose the work, in whole or in part and in any manner, and to have or permit others to do so, for government purposes pursuant to the copyright license under the clause at 252.227-7013.

For information about purchasing paper copies of SEI reports, please visit the publications portion of our Web site (http://www.sei.cmu.edu/publications/pubweb.html). 


\section{Contents}

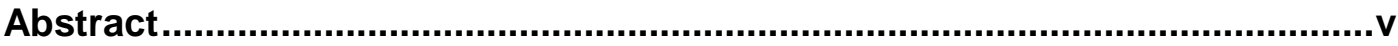

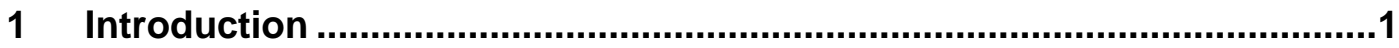

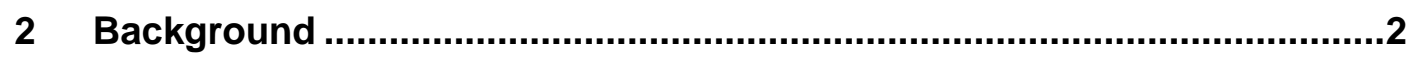

3 Migration-Planning Focus Areas Defined by the Prototype Program.......4

3.1 Migration Planning and Management .............................................. 4

3.2 Deployment and Transition Assistance .......................................

3.3 Database Conversion ................................................................. 5

3.4 Customer Relationship Management.........................................6

3.5 Management of the Legacy System Interface ..................................

3.6 Customer Training ....................................................................

4 Template for Moving to the Next Level of Detail...................................8

5 Evolution and Refinement of the Migration Plan ..................................

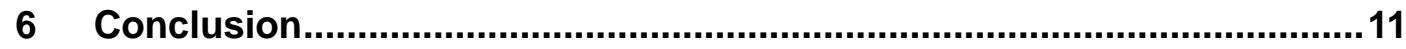

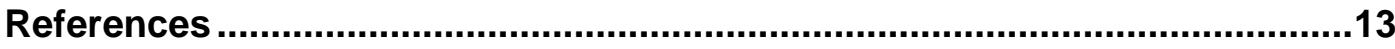




\section{List of Figures}

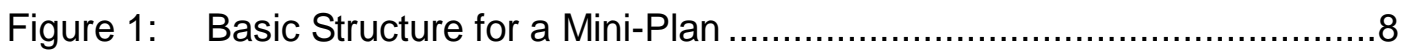

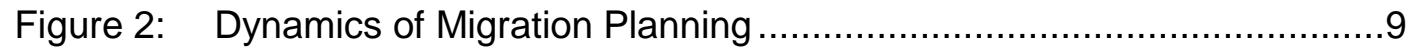

Figure 3: Relationship of Focus Areas and Mini-Plans to a Planning

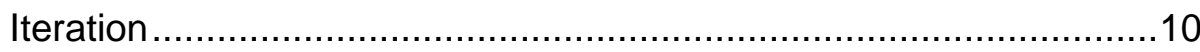




\section{Abstract}

In recent years, system modernization has received much attention within the Department of Defense (DoD). Typically, that attention has focused on the technical and acquisition issues associated with the new system. Less attention has been paid to the equally important issue of planning the migration from the old system to the new system.

This technical note reports on the early results of an approach that is currently being piloted to support software migration planning. This approach focuses on deriving actionable miniplans for focus areas that are identified in an initial increment of an overall migration plan. 


\section{Introduction}

In recent years, system modernization has received much attention within the Department of Defense (DoD). Typically, that attention has focused on the technical and acquisition issues associated with the new system. Less attention has been paid to the equally important issue of migration planning. A migration plan is necessary to provide guidance on how to phase out the legacy system and move to the new system.

A good software migration plan should

- clearly describe the approach for migrating users and operations from the legacy system to the new system

- contain sufficient detail to

- verify that the approach is complete, coherent, and consistent

- validate that the approach is on target

- provide a basis for

- communication and understanding among stakeholders

- managing resources and staff

- managing the project (i.e., internal view of the project)

- establishing the appropriate relationships with and commitments from stakeholders

- establishing a framework under which any related contract efforts can be managed

- provide a means for executive management to monitor the effort (i.e., external view of the project)

- reduce risk and increase the likelihood of a successful migration effort

This technical note describes the initial results of an approach to software migration planning that is currently being piloted in a major DoD organization. The approach enables migration planning to be managed proactively. It is an iterative approach that involves defining and refining mini-plans of action and adding new focus areas as circumstances change and the effort progresses. While this note is based on a specific migration example, the approach is also applicable to migration planning in general. 


\section{Background}

A large DoD organization is in the midst of a multi-year effort that involves a migration from a large number of legacy systems to a new consolidated system that will feature a common user interface with single-point access to the system. The legacy systems will be phased out over several years as different sets of new functionality become available.

The initial draft of the organization's migration plan identified the following major migration-planning factors:

- $\quad$ key tasks, roles, and responsibilities

- current environment

- new environment

- migration timing and prioritization

- migration policies

- $\quad$ risk factors

That draft provided a high-level overview for the overall migration effort, including the selection of an initial pilot for migration. However, it needed an additional level of detail to make it actionable and a mechanism for making it a "living document" that would evolve throughout the duration of the migration.

To get to the required level of detail, the team from the Software Engineering Institute (SEI) met with the migration team and prepared a set of checklists to address salient migration issues related to the development/migration cycle. These checklists helped to gain insights on the current status of the migration effort, how it was being coordinated with the development effort, and important issues and problems. Next, the SEI team analyzed the information and identified candidate software focus areas that appeared to be most relevant to the program's success. The SEI team presented the candidate focus areas to the migration team. After several iterations, both teams reached a consensus on an initial set of focus areas to pursue in some detail.

The migration team identified a set of associated activities for each focus area. Then the program manager assigned a team member to each area and asked that he or she develop a mini-plan of action for it.

Section 3 outlines the focus areas that were identified. Section 4 presents a template for driving the focus areas to the next level of detail and producing a mini-plan of action. Section 5 presents a model for performing the refinement of the migration plan. It proposes a spiral 
model that starts with an existing version of a migration plan and successively refines the plan for a set of focus areas. 


\section{Migration-Planning Focus Areas Defined by the Prototype Program}

Any migration effort will have a different set of priorities. For the pilot program, the team identified six critical focus areas through the process described in Section 2.

The software focus areas that we identified included

- migration planning and management

- deployment and transition assistance

- database conversion

- customer relationship management

- management of the legacy system interface

- customer training

We summarize these areas in the following subsections.

\subsection{Migration Planning and Management}

To ensure success, the migration effort needs to be actively managed. The mini-plans provide some structure for tracking the program on a continuous basis and are refined continuously to ensure their currency. This continuous refinement enables the migration plan to be a living document and not simply a document that represents a check mark on a list of planned deliverables.

The high-level activities for migration planning and management include

- Refine the migration plan.

- Assign the necessary roles and responsibilities.

- Identify, plan, and budget for needed resources.

- Track and document the migration's progress.

- Take corrective action, as needed, to reduce risk.

- Coordinate the migration effort across focus areas.

- Improve the migration process based on lessons learned.

- Continually evaluate the migration plan for completeness and update it as necessary. 
- Maintain a liaison with customer organizations.

\subsection{Deployment and Transition Assistance}

Because the cutover to a new system involves substantially more effort than merely turning off the old system and turning on the new system, a set of tasks is required to enable smooth deployment. These tasks involve identifying legacy systems and customer dependencies, mapping new capabilities to legacy customers, developing cutoff criteria, and finally performing the actual cutover.

The high-level activities for deployment and transition assistance include

- Identify the resources (both hardware and software) needed to deploy the new system.

- Identify where those resources will come from.

- Identify the parties responsible for deploying and sustaining those resources.

- Develop guidance for preparing the site and keeping the customer informed.

- Develop an approach for supporting both the old and new systems during the test period.

- Develop criteria for legacy system cutoff.

- Identify and prioritize cutover dates for the legacy system.

- Identify any customer dependencies on the legacy system.

- Map new capabilities to support legacy system customers:

- Identify needed high-level capabilities.

- Validate when the new system will support those capabilities.

- Work with the customers and assist them in developing their own transition plan to ensure buy-in and commitment.

- Perform customer familiarization exercises:

- Obtain insight into potential "show-stoppers," oversights, and problem areas.

- Incorporate lessons learned from initial rollouts of the migrated system to make the remaining migration effort more efficient and cost effective.

- Provide technical assistance to customers to help them fully transition to the new system.

- Track the cutoff criteria and validate criteria satisfaction.

- Cut off the legacy system.

\subsection{Database Conversion}

Database migration is particularly important in information systems. When migration involves conversion to a different database or the consolidation of multiple databases, the possibility of data inconsistencies is high. For this particular system, a large number of databases from different legacy systems were consolidated. 
The high-level activities for database conversion include

- Identify the volume of data to be converted.

- Identify the business rules that impact the data conversion.

- Identify schema differences between the new and old systems and their impact on the conversion.

- Analyze the work required for data cleanup and develop an approach for it.

- Identify the software utilities needed to assist in data conversion.

- Convert the databases.

- Document the process and results of the data conversion.

\subsection{Customer Relationship Management}

The consolidated system will have a large and diverse set of stakeholders. Different user communities have vastly different degrees of dependency on the existing systems as well as different understandings of the planned changes and the relationship of those changes to their work. Different user communities will be migrating to the new system at different times over the next several years. The success of the system update is highly dependent on acceptance by these diverse communities. As a result, plans for customer relationship management are critical to the program's success.

The high-level activities for customer relationship management include

- Identify any potential mandates that customers will need to follow.

- Inform customers of new releases and capabilities.

- Establish mechanisms for customer feedback.

- Formalize help-desk procedures and policies.

- Inform customers about available training and when it's being offered.

- Inform customers about the data conversion activities and when they are scheduled.

- Inform customers about the status of legacy system interfaces and how changes to the system may affect those interfaces.

- Identify the scope and extent of testing to ensure that the new system will be adequate. To do so, perform

- trial testing and

- production testing

- Establish mechanisms for handling new customer requirements. 


\subsection{Management of the Legacy System Interface}

This migration effort is complex not only because of the number of systems being consolidated, but also because of the large number of external systems that depend on it. Its outputs will be used by other systems across the DoD organization. Because the system is being designed to a modified set of requirements, a number of interface issues need to be resolved-determining which interfaces are required, resolving interface requirements in a timely manner, and predicting the effects of changed interfaces on customers.

The high-level activities for legacy system interface management include

- Identify the legacy systems that will require interfaces.

- Coordinate plans with owners of legacy systems.

- Identify system interfaces that have to be carried forward.

- Map interfaces to planned system releases.

- Identify any customer dependencies.

- Prioritize interface needs and coordinate them with development.

\subsection{Customer Training}

Each new release of the system will support a new set of users. Because of the diverse user population, each set of users has a different set of training needs. Users who require extensive interaction with the system for complex tasks will require classroom training in small groups. Other users who have a more casual need for the system may require less intensive training. Training needs to be synchronized with system releases and the availability of new system functionality.

The high-level activities for customer training include

- Scope the training and plan it to coordinate with system releases:

- Identify the training needed to support customers.

- Identify when training will be needed.

- Identify the types of training materials needed.

- Develop training materials including

- online training aids

- customer training courses

- Identify who will conduct the training.

- Provide guidance for the trainers.

- Pilot the training with the selected trainers and then evaluate the adequacy of both the training and the trainers. 


\section{Template for Moving to the Next Level of Detail}

The focus areas that were identified in Section 3 enabled the program manager to take the first step in actively managing the migration-planning effort. For each focus area, a responsible person was designated to develop a mini-plan of action down to additional levels of detail. The mini-plans need to answer the following questions:

- What needs to be done?

- Who is going to do it?

- How will it be done?

- How do we make sure that it is done satisfactorily?

The general structure for developing a mini-plan is shown in Figure 1.

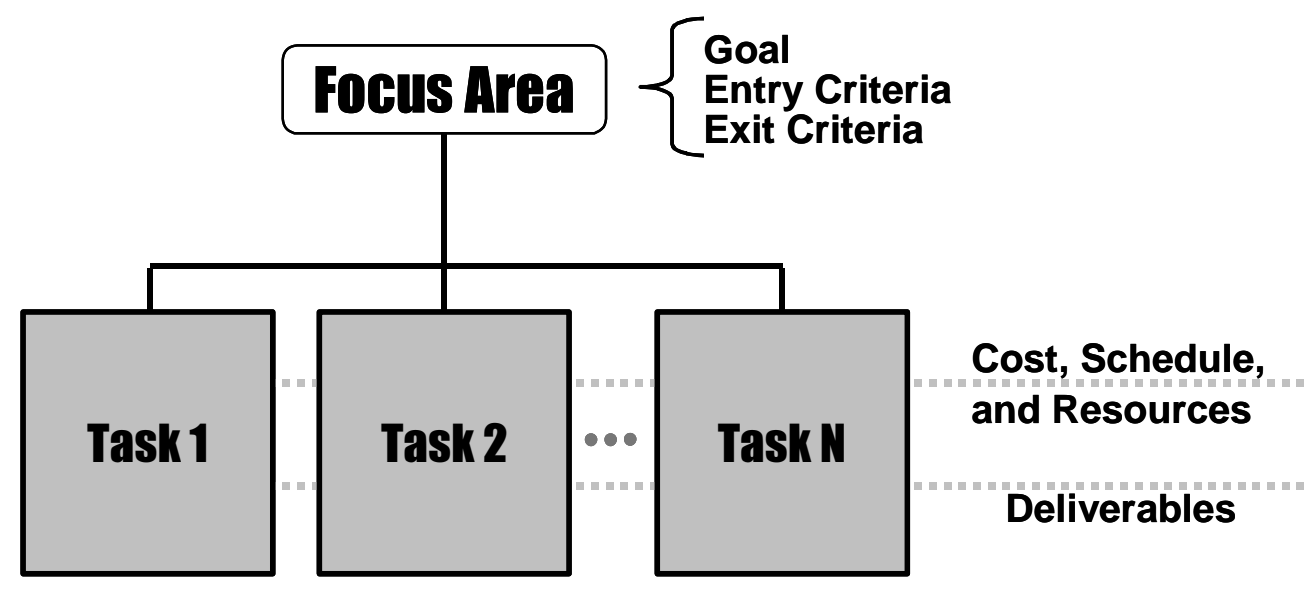

Figure 1: Basic Structure for a Mini-Plan

Each mini-plan is being developed according to the following template:

- focus area goal

- entry criteria

- $\quad$ work breakdown structure (WBS) for activities

- deliverables (products and services)

- roles and responsibilities

- cost, schedule, and resources

- $\quad$ artifacts and metrics for tracking progress

- exit criteria 


\section{Evolution and Refinement of the Migration Plan}

The approach that we have outlined takes an active and dynamic view of migration planning, which is a continuous effort that begins with the first increment of the migration plan. The overall process for migration plan refinement is illustrated in Figure 2.

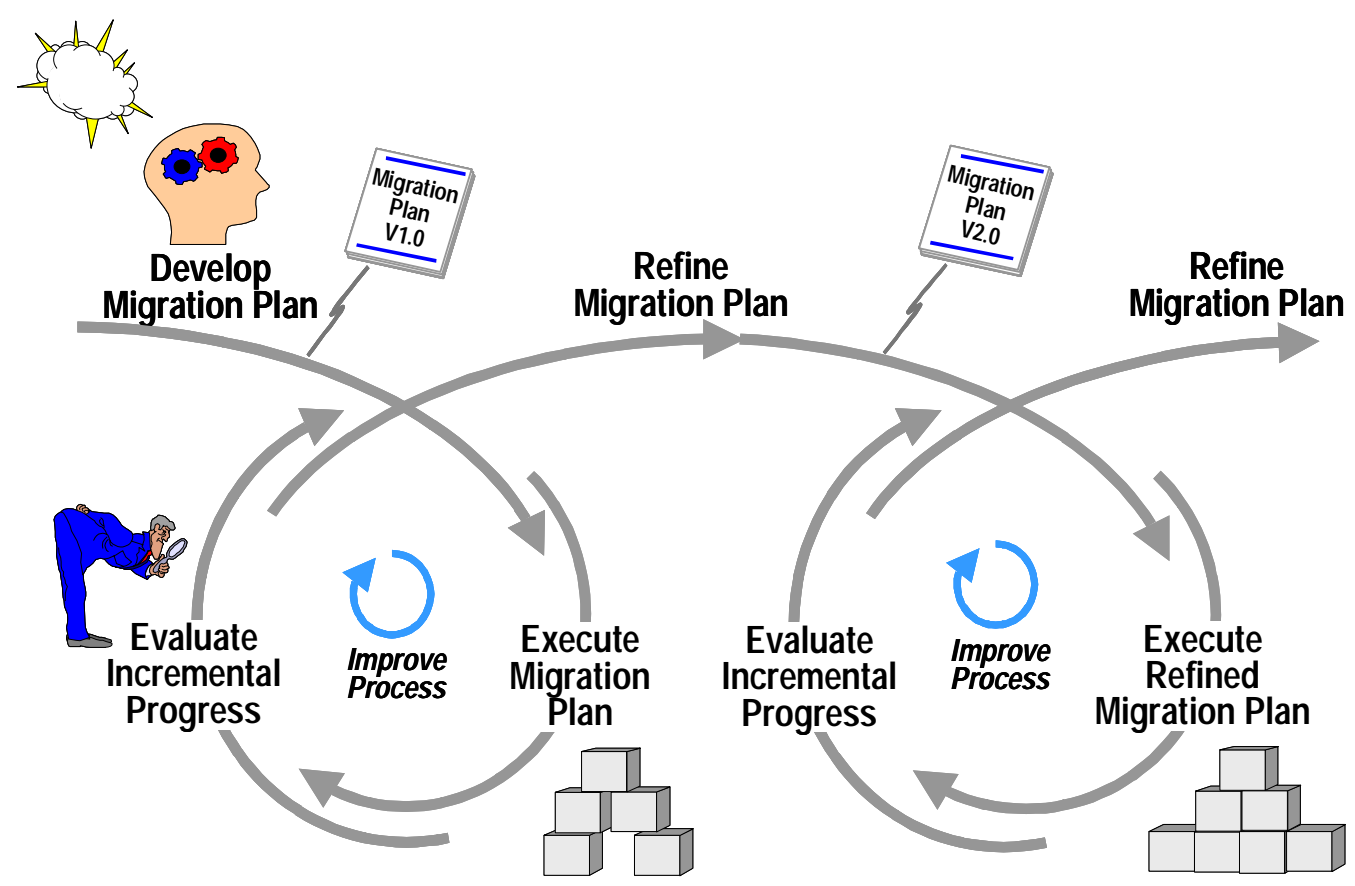

Figure 2: Dynamics of Migration Planning

The first increment of the plan identifies the primary issues and concerns. Successive iterations add more substance and make the plan actionable and manageable. Each iteration provides more elaboration in the form of detailed mini-plans of action for a set of focus areas that are most relevant to the project (e.g., high-priority areas). At any point in time, the migration plan can be viewed as the sum of the mini-plans of action.

The relationship of the focus areas and mini-plans to a particular iteration of the overarching migration plan is shown in Figure 3. As the mini-plans are executed, progress is evaluated and the migration plan is refined and updated. 


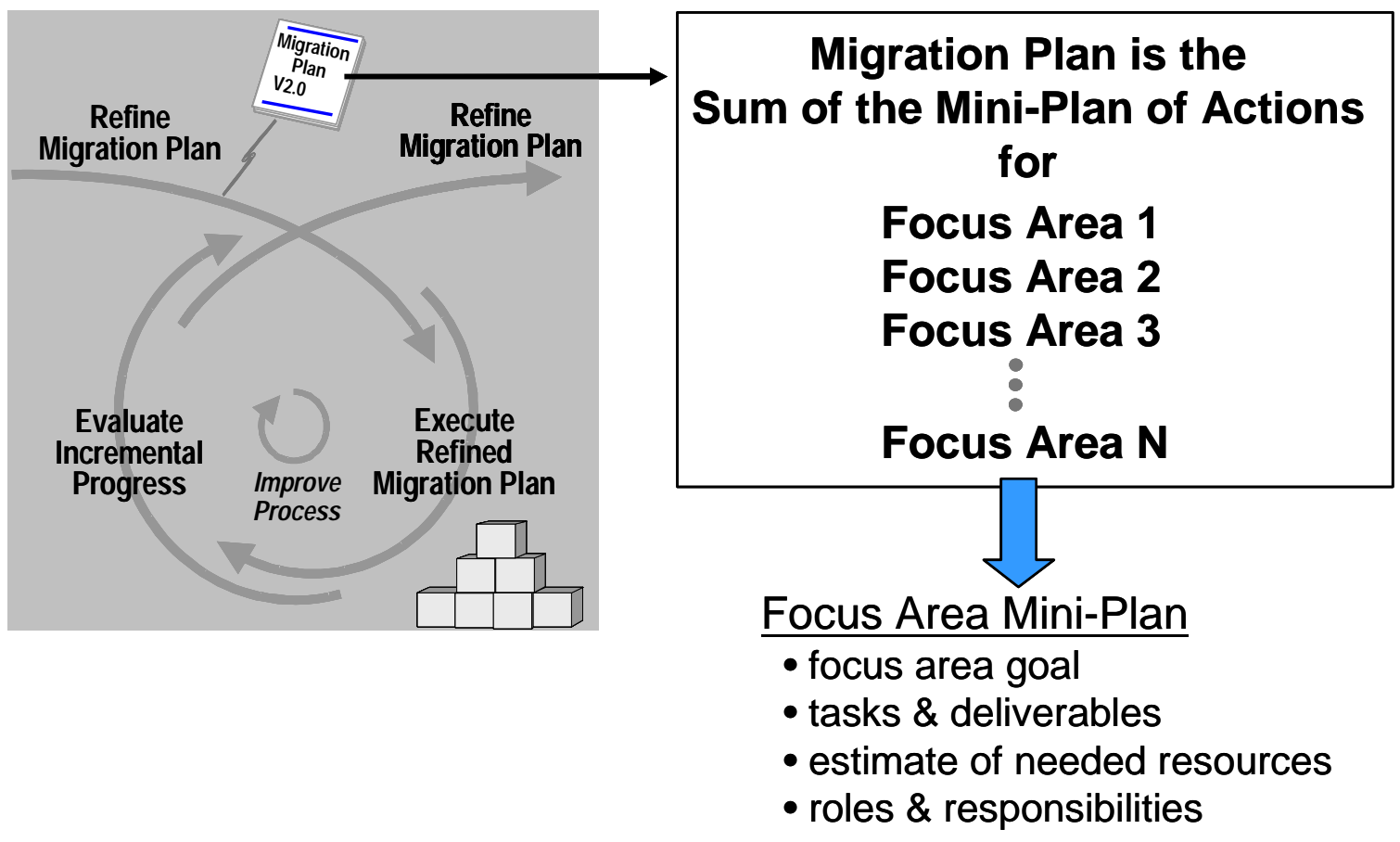

Figure 3: Relationship of Focus Areas and Mini-Plans to a Planning Iteration

Regular status reports for each mini-plan are developed using the following outline:

1. Focus Area Title

2. Goal of Focus Area

3. WBS for Activities

4. Status of Effort (By Task)

- technical progress (since last status update)

- current status of deliverables

- cost, schedule, and resources

5. Issues and Problems

- unresolved issues or technical problems (e.g., delays and deficiencies)

- cost, schedule, and resource implications

- dependencies or impact on other focus areas

- corrective action

6. Objectives for Next Review

- items to be completed

- problems and issues to be resolved 


\section{Conclusion}

This technical note has reported on an approach that is currently being piloted to support migration planning. This approach focuses on deriving actionable mini-plans for focus areas that are identified in an initial increment of a migration plan.

This note describes an initial round of migration planning. In subsequent iterations, some of the mini-plans may be found to be incomplete. An important purpose of the iterative approach is to improve the mini-plans as more information is obtained.

This iterative approach enables the migration planning to be managed proactively and involves refining the mini-plans of action and adding new focus areas as circumstances change and the effort progresses. It allows a program manager to obtain a "big picture" view of the high-level software migration activities and to understand and manage the details that need to be addressed to achieve a successful outcome. The continuous planning activity also surfaces risks in an organic way, so they can be dealt with effectively.

While this note is based on a specific migration example, the approach is also applicable to migration planning in general. 


\section{References}

[Bergey 01] Bergey, J. K.; O'Brien, L. M.; \& Smith, D. B. DoD Software Migration Planning (CMU/SEI-2001-TN-012, ADA395251). Pittsburgh, PA: Software Engineering Institute, Carnegie Mellon University, 2001.

<http://www.sei.cmu.edu/publications/documents/01.reports/01tn012.html>. 


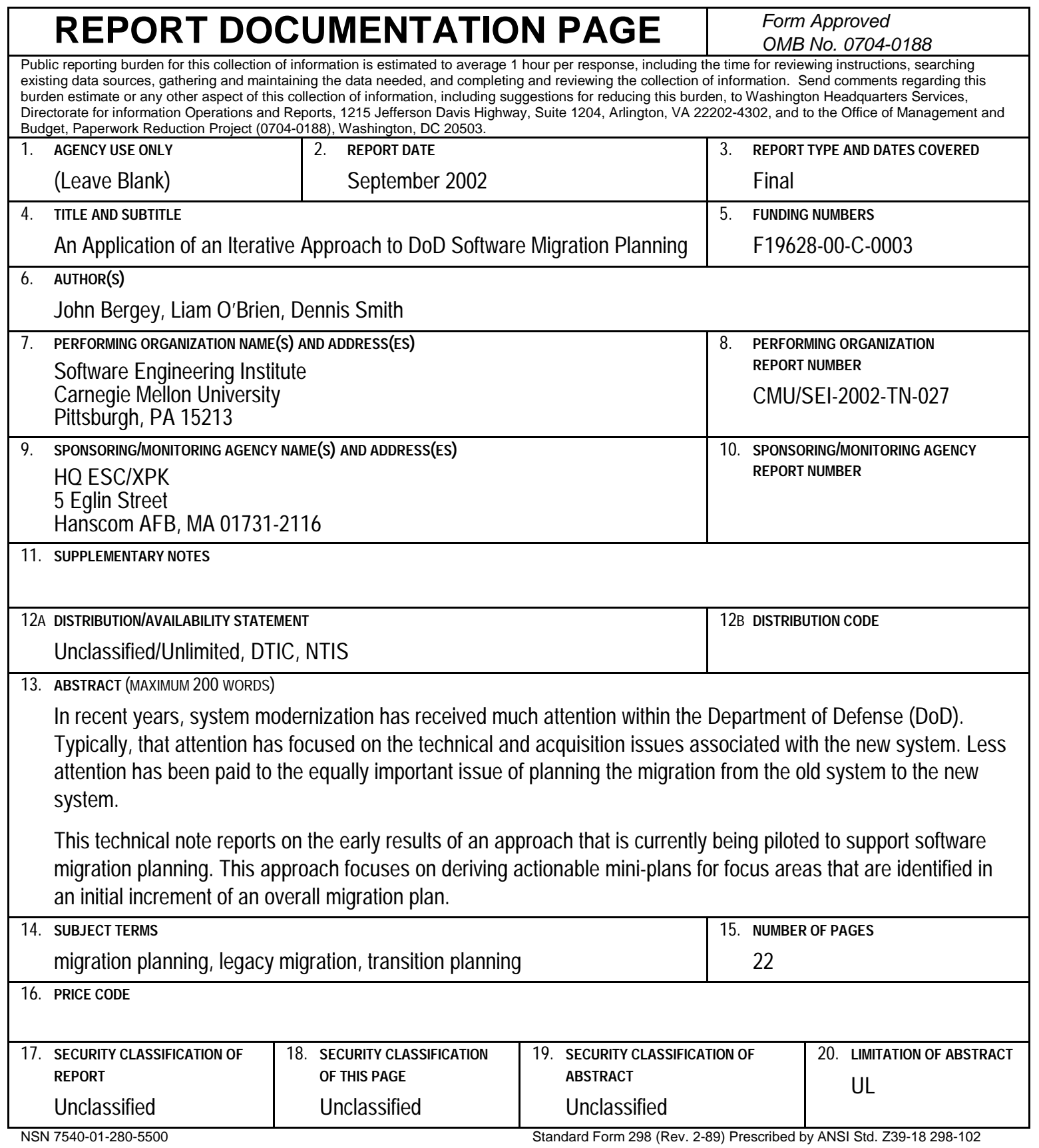

